\title{
Is household food insecurity a determinant of weight status in patients with type 2 diabetes in rural areas?
}

\author{
Ali Gholami ${ }^{1}$, Farhad Moradpour ${ }^{1,2}$, Maryam Khazaee-Pool ${ }^{3}$, Zahra Mousavi Jahromi ${ }^{4,5}$, \\ Mohammadreza Vafa6 ${ }^{6}$, Abbas Abbasi-Ghahramanloo ${ }^{1,7}$, Masoudreza Sohrabi ${ }^{8}$, \\ Nader Mahdavi ${ }^{1}$, Yousef Moradi ${ }^{1}$, Hamid Reza Baradaran ${ }^{1 *}$ \\ Received: 4 Dec 2016 \\ Published: 28 Dec 2017
}

\begin{abstract}
Background: There is mixed evidence about food insecurity and overweight/obesity coexisting, however it is unclear about association between food insecurity and weight status in people with type 2 diabetes. Therefore, the aim of this study was to evaluate the relationship between food insecurity and weight status in individuals with type 2 diabetes in rural areas in Iran.

Methods: 1847 patients with type 2 diabetes who were residence in rural areas completed Household Food Security Scale (six-item short questionnaire). Logistic regression model was applied to assess the independent effect of food insecurity on weight status.

Results: Mean age of the study population was $62.6 \pm 11.8$ years, and the majority of them were female $(70.4 \%)$. Most of the study population $(70.4 \%)$ had unhealthy weight status. Food insecurity affected more than $46 \%(\mathrm{n}=852)$ of the households of the study population. According to weight status, more than $40 \%(\mathrm{n}=565)$ of overweight and obese subjects and $60 \%(\mathrm{n}=18)$ of underweight subjects lived in households with food insecurity. The results of multiple logistic regression model showed that food insecurity was not an independent significant predictor of overweight or obesity in patients with type 2 diabetes. However, low food security (LFS) was an independent significant predictor for underweight in patients with type 2 diabetes $(\mathrm{OR}=2.35, \mathrm{P}=0.041)$.

Conclusion: It is concluded that food insecurity was frequent in all levels of weight status of patients with type 2 diabetes in rural regions. However this association observed in underweight individuals but there was no significant overall relationship between household food insecurity and in overweight and obesity in this group of patients.
\end{abstract}

Keywords: Food insecurity, Underweight, Overweight, Obesity, Type 2 diabetes

Copyright@ Iran University of Medical Sciences

Cite this article as: Gholami A, Moradpour F, Khazaee-Pool M, Mousavi Jahromi Z, Vafa M, Abbasi-Ghahramanloo A, Sohrabi M, Mahdavi N, Moradi Y, Baradaran HR. Is household food insecurity a determinant of weight status in rural type 2 patients with diabetes?. Med J Islam Repub Iran. 2017 (28 Dec);31:138. https://doi.org/10.14196/mjiri.31.138

\section{Introduction}

Overweight and obesity are major public health issues which its prevalence is intensely increasing in the world (1) and efforts to decrease the spread demonstrate a priority of the public health issue. Overweight/obesity is related to the prevalence of chronic diseases, including cancers, type 2 diabetes, and cardiovascular disease (2). Obesity is defined as the fat increase in a too much shape in adipose tissue; it may cause some serious health worries that can

Corresponding author: Dr Hamid Reza Baradaran, baradaran.hr@iums.ac.ir

1. Department of Epidemiology, School of Public Health, Iran University of Medical Sciences, Tehran, Iran.

2. Social Determinants of Health Research Center, Kurdistan University of Medical Sciences, Sanandaj, Iran.

3. Department of Health Education and Promotion, School of Health, Zanjan University of Medical Sciences, Zanjan, Iran.

4. Health Management and Economics Research Center, Iran University of Medical Sciences, Tehran, Iran.

5. School of Public Health, Zabol University of Medical Sciences, Zabol, Iran

6. Department of Nutrition, School of Public Health, Iran University of Medical Sciences, Tehran, Iran.

Department of Epidemiology, School of Public Health, Ardabil University of Medical Sciences, Ardabil, Iran.

8. Gastrointestinal \& Liver Disease Research Center (GILDRC), Firoozgar Hospital, Iran University of Medical Sciences, Tehran, Iran. vary from a disability to death (1). Remarkable consideration is being focused on the obesity complications in atrisk people (3). Causes of the rise in overweight/obesity are not completely understood, even though the low level of exercise and eating high-fat foods or using carbohydrates are believed to be participating factors (4). However, it has also been recommended that overweight/obesity may happen because of inadequate food accessibility, and

$\uparrow$ What is "already known" in this topic:

There have a limited number of studies investigating the relationship of weight status with food insecurity in patients with type 2 diabetes, and they have revealed conflicting and complex results.

$\rightarrow$ What this article adds:

The findings of this study emphasize the necessity to consider household food insecurity as an effective factor related to underweight among the individuals with type 2 diabetes who live in rural areas. 
Table 1. Items of household food security short questionnaire

Item

1 In the last 12 months, did you or any other in your household ever had to cut the size of your meals or skipped meals entirely because there was not enough money for food?

2 If yes, how often did this happen?

3 In the last 12 months, did you ever eat less than you felt you should because there was not enough money to buy food?

4 In the last 12 months, were you ever hungry, but did not eat because you could not afford enough food?

5 The food that I/we bought just did not last, and I/we did not have money to get more. Was this often, sometimes, or never true for you or the other members of your household in the last 12 months?

6 I/we could not afford to eat balanced meals. Was this often, sometimes, or never true for you or the other members of your household in the last 12 months?

this happens if food insecurity leads to an intake of obesity-enhancing foods (5). Food security is a condition in which individuals have the accessibility of adequate and nourishing diet for a healthy life at all times (6). Food insecurity has been related to lower dietary intakes of vital foods (7). Various factors can be associated with food insecurity (such as economic, social and environmental factors) (8-10). Food insecurity has limited availability or accessibility of food in socially appropriate means. Over time, these fewer consumptions could increase the risk of developing diet-related to chronic diseases. Food insecurity could have a bad effect on well-being (11). Additionally, food insecurity has been related to poor disease controlling in persons with chronic diseases like diabetes (12). People with food insecurity may consume more calorically dense food which allowing individual potentially access higher bodyweight (13). Studies have shown that the risk of type 2 diabetes is increased with overweight/obesity (14-15). Despite of the increasing numbers of overweight and obese individuals, the underweight population was also observed in same households (16-17). Therefore, it is possible that we observe underweight and overweight people in food secure or insecure households.

There have found a limited number of studies investigating relationship of overweight/obesity and underweight with food insecurity in type 2 patients with diabetes, and they have revealed conflicting and complex results. Although the significant relationships between food insecurity with overweight/obesity and underweight were reported in some studies $(12,18-20)$, the other studies did not report any significant relationship (21-23), or it was found an opposite association (24). The effects of overweight/obesity, underweight and food insecurity are damaging to health. The bad health consequences resulting from overweight/obesity, underweight and food insecurity are sometimes permanent and may result in a decreases in the quality of life and well-being (3).

Given that few studies have investigated in the area of

Table 2. Characteristics of study population by their weight status

\begin{tabular}{|c|c|c|c|c|c|c|}
\hline \multirow[t]{2}{*}{ Variable } & \multicolumn{2}{|c|}{$\begin{array}{c}\text { All } \\
(n=1847)\end{array}$} & \multirow{2}{*}{$\begin{array}{c}\begin{array}{c}\text { Normal } \\
(\mathrm{n}=547)\end{array} \\
\mathrm{N}(\%)\end{array}$} & \multirow{2}{*}{$\begin{array}{c}\begin{array}{c}\text { Underweight } \\
(\mathrm{n}=30)\end{array} \\
\mathrm{N}(\%)\end{array}$} & \multirow{2}{*}{$\begin{array}{l}\begin{array}{c}\text { Overweight } \\
(\mathrm{n}=809)\end{array} \\
\mathrm{N}(\%)\end{array}$} & \multirow{2}{*}{$\begin{array}{c}\begin{array}{c}\text { Obese } \\
(\mathrm{n}=461)\end{array} \\
\mathrm{N}(\%)\end{array}$} \\
\hline & No & $\%$ & & & & \\
\hline \multicolumn{7}{|l|}{ Sex } \\
\hline Male & 547 & 29.6 & $164(30)$ & $14(2.6)$ & $252(46.1)$ & $117(21.4)$ \\
\hline Female & 1300 & 70.4 & $383(29.5)$ & $16(1.2)$ & $557(42.8)$ & $344(26.5)$ \\
\hline \multicolumn{7}{|l|}{ Age } \\
\hline$\leq 62 \mathrm{y}$ & 993 & 53.8 & $243(24.5)$ & $14(1.4)$ & $455(45.8)$ & $281(28.3)$ \\
\hline$>62 \mathrm{y}$ & 854 & 46.2 & $304(35.6)$ & $16(1.9)$ & $354(41.5)$ & $180(21.1)$ \\
\hline \multicolumn{7}{|l|}{ Marital status } \\
\hline Married & 1471 & 79.6 & $406(27.6)$ & $18(1.2)$ & $664(45.1)$ & $383(26)$ \\
\hline Single ${ }^{* *}$ & 376 & 20.4 & $141(37.5)$ & $12(3.2)$ & $145(38.6)$ & $78(20.7)$ \\
\hline \multicolumn{7}{|l|}{ Education levels } \\
\hline Illiterate & 1229 & 66.5 & $389(31.7)$ & $23(1.9)$ & $543(44.2)$ & $274(22.3)$ \\
\hline Elementary or above & 618 & 33.5 & $158(25.6)$ & $7(1.1)$ & $266(43)$ & $187(30.3)$ \\
\hline \multicolumn{7}{|l|}{ Current cigarette use } \\
\hline No & 1361 & 73.7 & $387(28.4)$ & $27(2)$ & $612(45)$ & $335(24.6)$ \\
\hline Yes & 486 & 26.3 & $160(32.9)$ & $3(0.6)$ & $197(40.5)$ & $126(25.9)$ \\
\hline \multicolumn{7}{|l|}{ Household income*** } \\
\hline$<200 \$$ & 1476 & 79.9 & $459(31.1)$ & $26(1.8)$ & $642(43.5)$ & 349 (23.6) \\
\hline$\geq 200 \$$ & 371 & 20.1 & $88(23.7)$ & $4(1.1)$ & $167(45)$ & $112(30.2)$ \\
\hline \multicolumn{7}{|l|}{ Family size* } \\
\hline$\leq 3$ & 984 & 58.5 & $322(32.7)$ & $18(1.8)$ & 417 (42.4) & $227(23.1)$ \\
\hline$>3$ & 699 & 41.5 & $176(25.2)$ & $9(1.3)$ & $318(45.5)$ & $196(28)$ \\
\hline \multicolumn{7}{|l|}{ Duration of disease } \\
\hline$<10 y$ & 1114 & 60.3 & $282(25.3)$ & $16(1.4)$ & $513(46.1)$ & $303(27.2)$ \\
\hline$\geq 10 y$ & 733 & 39.7 & $265(36.2)$ & 14 (1.9) & $296(40.4)$ & $158(21.6)$ \\
\hline \multicolumn{7}{|l|}{ Food insecurity } \\
\hline HFS & 995 & 53.9 & $278(27.9)$ & $12(1.2)$ & $446(44.8)$ & $259(26)$ \\
\hline LFS & 433 & 23.4 & $134(30.9)$ & $4(0.9)$ & $184(42.5)$ & $111(25.6)$ \\
\hline VLFS & 419 & 22.7 & $135(32.2)$ & $14(3.3)$ & $179(42.7)$ & $91(21.7)$ \\
\hline
\end{tabular}

*Some data were missing in these variables. ** Including single, widow and divorced.

$* * * 200 \$=6000000$ Rials.

Abbreviations: High or marginal Food Security (HFS), Low Food Security (LFS), Very Low Food Security (VLFS) 
food insecurity, overweight/obesity and underweight among patients with type 2 diabetes with mixed results therfeore this study aimed to assess the relationship between of food insecurity with overweight/obesity and underweight in people with type 2 diabetes who live in rural areas in northeast of Iran.

\section{Methods}

This survey was carried out on 1847 patients with type 2 diabetes. These patients were recruited and selected from health centers in rural regions of Neyshabur city located in northwest of Iran .

Then, data were gathered through home interviews by trained researchers. All participants were informed about the purpose of this study. Additionally, verbal consent was taken from all patients to take part in this study. A final sample was recruited to have the following eligibility criteria: diagnosed with type 2 diabetes, age 30 years or more at the time of data detection, placed in Neyshabur rural regions (six months prior to interview), having no audiovisual problems and agree to participate in the study. Socio-demographic information including; age, gender, marital status, education levels, current cigarette status, household income, family size, duration of disease and anthropometric data were asked.

The anthropometric assessment was performed according to the CDC (25) measures that included the weight and height of all eligible patients with type 2 diabetes in the selected households. Standing height was assessed using a stadiometer with 1-mm accuracy. Weights were calculated with a digital scale with 100 -g accuracy. From these dimensions, the body mass index (BMI) was measured, as weight $(\mathrm{kg}) /$ height $(\mathrm{m} 2)$. Patients were categorized as underweight (BMI $<18.5 \mathrm{~kg} / \mathrm{m} 2)$, normal weight $(\mathrm{BMI}=18.5$ $24.9 \mathrm{~kg} / \mathrm{m} 2)$, overweight $(\mathrm{BMI}=25.0-29.9 \mathrm{~kg} / \mathrm{m} 2)$, and obese (BMI $\geq 30 \mathrm{~kg} / \mathrm{m} 2)$.

Persian version of Household Food Security Scale (sixitem short questionnaire) was applied for assessing household food security in the study population (Table 1) (26).

Households were classified as 'food-insecure' if the respondent answered positively to two or more of the 6 household food security questions. For questions, number 1, 3 and 4, "Yes" was regarded as positive answers, and for item number 2 "Almost every" and "some months" were positive answers. "Often" and "sometimes" were noted positive answers for items five and six.

Households that reply to all items negatively or just a positive answer, were classified as high or marginal food security (HFS), households with 2-4 positive answer were classified as low food security (LFS), and those answered 5-6 positive answer were classified as very low food security (VLFS).

Multiple logistic regression model was also applied to assess the effect of food insecurity on weight status. Pvalues less than 0.2 in univariate analyses and less than 0.05 in multiple analyses were considered as statistically significant.

\section{Results}

\section{Characteristics of the Study population}

Table 2 presents the descriptive statistics for surveyed variables as well as subject demographics. The mean \pm SD age of our study population was $62.6 \pm 11.8$ years. Female patients made up the majority of the study population (70.4\%). Almost one in five patients was living alone. Based on the percentile cutoffs for BMI, as suggested by the CDC, most individuals (70.4\%) in the study population were considered to have an unhealthy weight status (1.6\% of them was underweight, $43.8 \%$ was overweight, and $25 \%$ was obese) while just $29.6 \%(n=547)$ of the subjects had the healthy weight (normal weight). Food insecurity affected approximately $46.1 \% \quad(n=852)$ of the households of the study population. According to weight status, more than $40 \%(n=565)$ of overweight and obese subjects and $60 \%(n=18)$ of underweight subjects lived in households with food insecurity (Fig. 1). Participants in households with food insecurity had a BMI of 27.0 (SD = 4.8) on average, compared to participants in households with food security who had an average BMI of 27.3 (SD = 4.5) $(\mathrm{p}=0.2)$.

\section{Univariate associations}

Associations between weight status of patients with type 2 diabetes and the surveyed variables are listed in Table 3 . The results show that VLFS had an association with underweight, overweight and obesity in the patients $(\mathrm{p}<0.2)$. But, the LFS did not have an association with underweight, overweight and obesity in the patients $(p>0.2)$.

\section{Results from multiple logistic regression models}

Results from the multiple logistic regression models have shown in Table 4. Food insecurity (LFS \& VLFS) was not a significant predictor for overweight or obesity in patients with type 2 diabetes, as controlled for potential confounders. Nonetheless, food insecurity (VLFS) was a

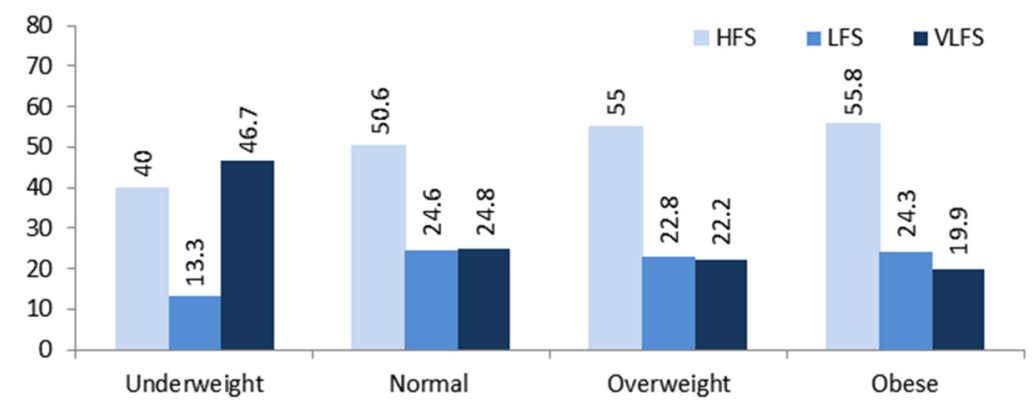

Fig. 1. Distribution of samples according to food security and weight status 
Table 3. Unadjusted odds ratio (OR) estimates of different variables based on univariate analyses

\begin{tabular}{|c|c|c|c|c|c|c|c|}
\hline \multirow{2}{*}{\multicolumn{2}{|c|}{ Variable }} & \multicolumn{2}{|c|}{ Underweight } & \multicolumn{2}{|c|}{ Overweight } & \multicolumn{2}{|c|}{ Obese } \\
\hline & & $\begin{array}{c}\text { OR } \\
(95 \% \mathrm{CI})\end{array}$ & $\mathrm{p}$ & $\begin{array}{c}\text { OR } \\
(95 \% \mathrm{CI})\end{array}$ & $\mathrm{p}$ & $\begin{array}{c}\text { OR } \\
(95 \% \mathrm{CI})\end{array}$ & $\mathrm{p}$ \\
\hline \multicolumn{2}{|l|}{ Sex (Female) } & $\begin{array}{c}0.49 \\
(0.23,1.03)\end{array}$ & 0.058 & $\begin{array}{c}0.95 \\
(0.75,1.20)\end{array}$ & 0.647 & $\begin{array}{c}1.26 \\
(0.95,1.66)\end{array}$ & 0.11 \\
\hline \multicolumn{2}{|l|}{ Age $(>62$ y) } & $\begin{array}{c}0.91 \\
(0.44,1.91)\end{array}$ & 0.810 & $\begin{array}{c}0.62 \\
(0.50,0.77)\end{array}$ & $<0.001$ & $\begin{array}{c}0.51 \\
(0.40,0.66)\end{array}$ & $<0.001$ \\
\hline \multicolumn{2}{|c|}{ Marital status (Single)* } & $\begin{array}{c}1.92 \\
(0.90,4.09)\end{array}$ & 0.091 & $\begin{array}{c}0.63 \\
(0.48,0.82)\end{array}$ & 0.001 & $\begin{array}{c}0.59 \\
(0.43,0.80)\end{array}$ & 0.001 \\
\hline \multicolumn{2}{|c|}{ Education levels ( Elementary or above) } & $\begin{array}{c}0.75 \\
(0.32,1.78)\end{array}$ & 0.514 & $\begin{array}{c}1.21 \\
(0.95,1.53)\end{array}$ & 0.120 & $\begin{array}{c}1.68 \\
(1.29,2.18)\end{array}$ & $<0.001$ \\
\hline \multicolumn{2}{|c|}{ Current cigarette use (Yes) } & $\begin{array}{c}0.27 \\
(0.08,0.90)\end{array}$ & 0.033 & $\begin{array}{c}0.78 \\
(0.61,0.99)\end{array}$ & 0.045 & $\begin{array}{c}0.91 \\
(0.69,1.20)\end{array}$ & 0.50 \\
\hline \multicolumn{2}{|c|}{ Household income $(\geq 200 \$)$} & $\begin{array}{c}0.80 \\
(0.27,2.36)\end{array}$ & 0.689 & $\begin{array}{c}1.36 \\
(1.02,1.80)\end{array}$ & 0.036 & $\begin{array}{c}1.67 \\
(1.23,2.29)\end{array}$ & 0.001 \\
\hline \multicolumn{2}{|l|}{ Family size $(>3)$} & $\begin{array}{c}0.92 \\
(0.40,2.08)\end{array}$ & 0.832 & $\begin{array}{c}1.40 \\
(1.10,1.76)\end{array}$ & 0.005 & $\begin{array}{c}1.58 \\
(1.21,2.06)\end{array}$ & 0.001 \\
\hline \multicolumn{2}{|c|}{ Duration of disease $(\geq 10 \mathrm{y})$} & $\begin{array}{c}0.93 \\
(0.45,1.95)\end{array}$ & 0.849 & $\begin{array}{c}0.61 \\
(0.49,0.77)\end{array}$ & $<0.001$ & $\begin{array}{c}0.56 \\
(0.43,0.72)\end{array}$ & $<0.001$ \\
\hline \multirow[t]{2}{*}{ Food insecurity } & LFS & $\begin{array}{c}0.69 \\
(0.22,2.18)\end{array}$ & 0.53 & $\begin{array}{c}0.86 \\
(0.65,1.12)\end{array}$ & 0.256 & $\begin{array}{c}0.89 \\
(0.66,1.20)\end{array}$ & 0.447 \\
\hline & VLFS & $\begin{array}{c}2.40 \\
(1.08,5.34)\end{array}$ & 0.031 & $\begin{array}{c}0.83 \\
(0.63,1.08)\end{array}$ & 0.165 & $\begin{array}{c}0.72 \\
(0.53,0.99)\end{array}$ & 0.044 \\
\hline
\end{tabular}

* Including single, widow and divorced

Abbreviations: OR (Odds Ratio), P.v (P.value), Low Food Security (LFS), Very Low Food Security (VLFS)

Table 4. Adjusted odds ratio (OR) estimates of different variables based on multiple logistic regression analyses

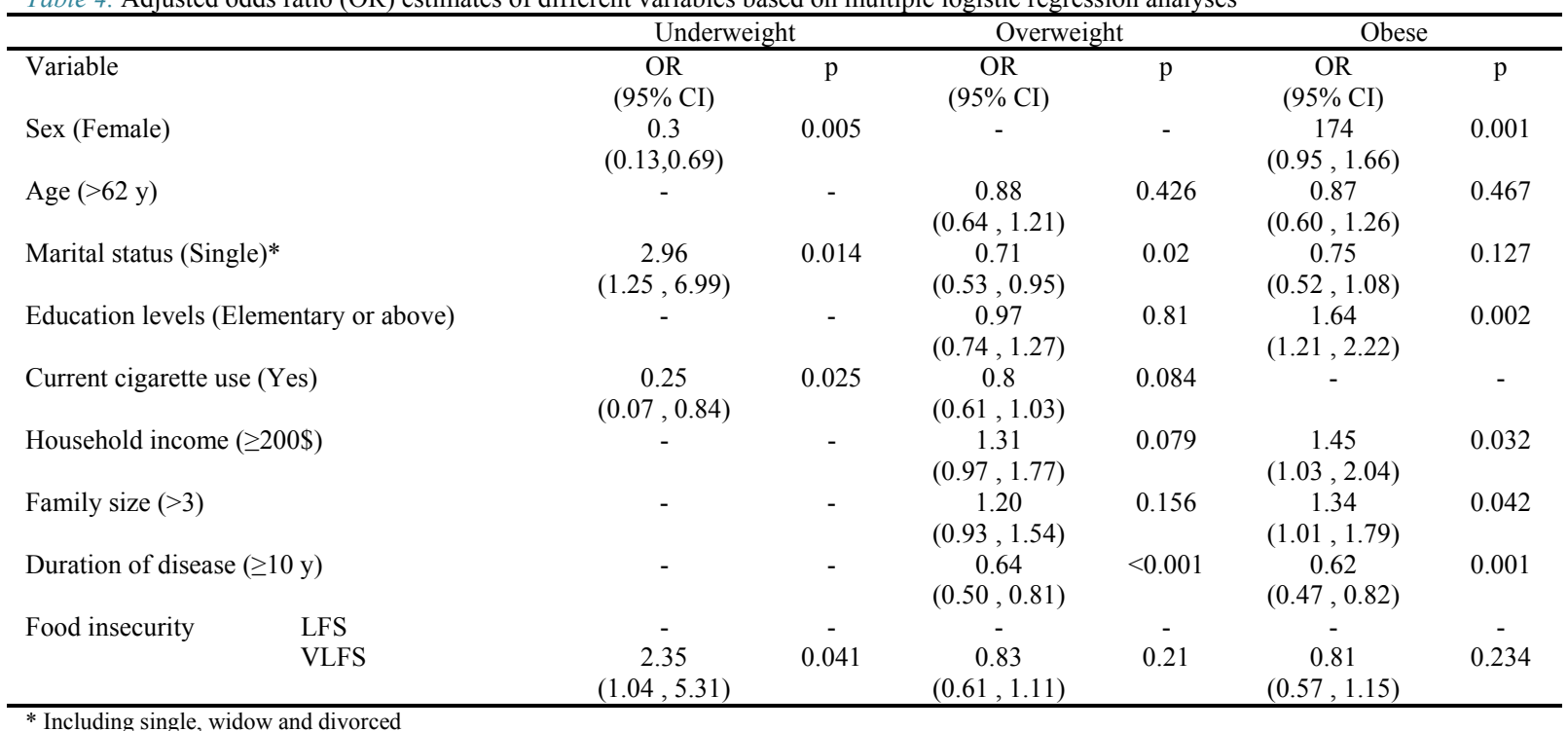

* Including single, widow and divorced

Abbreviations: OR (Odds Ratio), P.v (P.value), Low Food Security (LFS), Very Low Food Security (VLFS)

significant predictor for the patients with underweight. Odds of underweight in patients with diabetes who lived in food-insecure households were over twice compared to those who lived in food-secure households $(\mathrm{OR}=2.35$, 95\% CI: 1.04- 5.31, $\mathrm{p}=0.041$ ).

\section{Discussion}

The findings of study have shown that the prevalence of household food insecurity in people with type 2 diabetes who reside in rural areas is in almost 46 percent. Prevalence of food insecurity for normal weight, underweight, overweight and obese people with diabetes were $49.2 \%, 60 \%, 45 \%$, and $44.2 \%$, respectively. Other studies reported vary prevalence for example Cheng S., et al. (27) reports that $32 \%$ of their study population was food insecure and the majority of them were severely food- insecure. Similar prevalences from other studies has been reported as $46 \%$ for US (28), $52.4 \%$ for Latinos (29) and $77 \%$ for Jordan (30).

Investigating socioeconomic status of the study population may reveal possible explanation of high prevalence of food insecurity. Participants in our study may spend some part of their income on the medications that make them susceptible to food insecurity. Other studies found that poverty and low socioeconomic status are major causes of food insecurity in the population (31-32). Moreover, other factors such as gender, education level, duration of the disease have direct relationships with income (30).

The vast majority of the studies conducted in the Iranian population reports lower food insecurity values compared to the present study (33-37). The higher levels of food insecurity in our study compared to other published data 
may be as a result of the nature of sample which was composed of patients with diabetes rather than healthy people. Participant in this study may spend a lot of their income on medicines to treat diabetes and its complication, which make them prone to food insecurity. All participants of this study also lived in rural regions that may be an effective factor in relation to food insecurity, because rural populations have lower income in comparison to urban populations.

Other factors associated with food insecurity are gender, age, education level and income $(30,38)$. As displayed in Table 2, the majority of our participant are female $(70.4 \%)$, old (age $>62=46.2 \%)$, with low education level (most are illiterate) and from household with low income (annually $<200 \$$ ).

An interesting result emerges when food insecurity was investigated in the different categories of weight status. In this study, the percentage of VLFS in normal, overweight and obese patients were relatively similar, but it is very different (more than 46\%) in underweight patients. After controlling for age, sex, household income and other important confounders (Table 4), VLFS remained as an important risk factor for underweight, while for overweight and obesity it was a non-significant protective factor. This is in contrast with studies conducted in healthy subjects. The study that conducted by Laraia BA et al. (39) showed a linear positive association between food insecurity and obesity level. Other results found that persons who suffer from LFS were more likely to be overweight (40-42).

However, few studies examined the link between food insecurity and weight status in patients with diabetes. This relationship remains controversial and may vary between low- and high-income countries (43). While some studies display a positive relation, others, such as the present study, display negative associations. In a study conducted on two Iranian ethnic groups, a different association was observed between food insecurity and weight status for Kurdish and Turkish ethnicity. Moderate and severe food insecurity increases the chance of obesity in Turkish while decreases general obesity in Kurdish people (44). Cheng et al. (27) found that patients with diabetes suffering from food insecurity were more likely to be underweight. So, more percentages of food insecure individuals were in lower categories of weight status than food secured patients. A similar study by Bawadi (30) was found that higher BMI is found in severely food insecure patients as compared to food secture and moderately food insecure patients. Other studies conducted in the children (45) and adult (46) with diabetes found no significant differences between food secured and food insecure households. Conversely, some studies revealed a U-shaped pattern, while food security decline to the moderate level, body weight increased to the higher level, and in VLFS persons tend to have lower BMI $(47,48)$.

Among healthy people, food insecurity may be associated with lower dietary quality and poor nutritional intake but with consumptions of more calorically dense food materials potentially leading to higher bodyweight (13). Whereas in patients with diabetes, VLFS may be related to a reduction in food intake (49). Food insecure in patients with diabetes has marginally higher HbA1C level (more than 7), therefore they are at higher risk for poorer glycemic control and more susceptible to peripheral insulin resistance. Over time this may lead to failure of producing insulin beta-cells. In such circumstances, the brain evolutionary mechanisms in trying to provide the necessary energy for body vital function destroyed the subcutaneous fat and muscle tissue and resulted in less body weight $(50,51)$.

There are some methodological limitations in present study. First, food insecurity was measured as a household scale while the weight status is an individual-level outcome. When there is some level of food insecurity in a household, most (but not all) of the family members are usually affected. Second, in the present cross-sectional study the temporality assumption of data collection was not hold; therefore we cannot determine which of the two factors, food insecurity or obesity, is prior to the other.

Due to the limitation in the number of food insecurity studies on the diabetes population, more population-based prospective cohort study with large sample size are needed to explain how the food security status affects patients with diabetes, particularly with regard to the adverse outcomes such as underweight, overweight and obesity.

\section{Conclusion}

The results of this study have shown that food insecurity was frequent in all levels of weight status of patients with type 2 diabetes in rural areas and was associated with underweight but not with overweight and obesity. Furthermore, this study emphasizes the necessity to consider household food accessibility as a part of programs to improve healthy food choices and good health among the patients with type 2 diabetes particularly in rural areas.

\section{Acknowledgments}

The authors would like to express their gratitude to all patients with diabetes that contributed to this study. This study also was granted by Iran University of Medical Sciences number 94-02-27-26060.

\section{Conflict of Interests}

The authors declare that they have no competing interests.

\section{References}

1. James WP. The epidemiology of obesity: the size of the problem. Journal of internal medicine. 2008;263(4):336-52.

2. Centers for Disease Control and Prevention. Public health and aging: trends in aging: United States and worldwide. JAMA. 2003;11:13711373.

3. Ogden CL, Carroll MD, Curtin LR, McDowell MA, Tabak CJ, Flegal KM. Prevalence of overweight and obesity in the United States, 19992004. JAMA. 2006;295:1549-1555

4. Bhattacharya J, Currie J, Haider S. Poverty, food insecurity, and nutritional outcomes in children and adults. $\mathrm{J}$ Health Econ. 2004;23:839-62.

5. Dietz WH: Does hunger cause obesity? Pediatrics 1995, 95:766-767.

6. Swindale A, Bilinsky P: Household Dietary Diversity Score (HDDS) for Measurement of Household Food Access: Indicator Guide V. 2 Washington DC: Food and Nutrition Technical Assistance Project; 
2006

7. Drewnowski A, Specter SE. Poverty and obesity: The role of energy density and energy costs. Am J ClinNutr. 2004;79:6-16.

8. Sharafkhani R, Dastgiri S, Gharaaghaji Asl R, Ghavamzadeh S. Factors influencing household food security status. Food Nutr Sci. 2011;2:31-4.

9. Gholami A, Rezaei Sani T, Askari M, Moosavi Jahromi, Dehghan A. Food insecurity status and associated factors among rural households in North-East of Iran. Int J Prev Med. 2013;4:1018-24.

10. Furness BW, Simon PA, Wold CM, Asarian-Anderson J. Prevalence and predictors of food insecurity among low-income households in Los Angeles County. Public Health Nutr. 2004;7:791-4.

11. Dixon LB, Winkleby MA, Radimer KL. Dietary intakes and serum nutrients differ between adults from food-insufficient and foodsufficient families: Third National Health and Nutrition Examination Survey, 1988-1994. J Nutr. 2001;131:1232-46.

12. Casey PH, Simpson PM, Gossett JM, Bogle ML, Champagne CM, Connell $\mathrm{C}$ et al. The association of adolescent and household food insecurity with adolescent overweight status. Pediatrics. 2006;118:1406-13.

13. Drewnowski A, Darmon N. The economics of obesity: dietary energy density and energy cost. Am J ClinNutr. 2005;82:265S-73S.

14. Centers for Disease Control and Prevention. BMI for Adults. Atlanta (GA) Available from: http://www.cdc.gov/healthyweight/ assessing/bmi/index.html.

15. Holben DH, Pheley AM. Diabetes risk and obesity in food-insecure households in rural Appalachian Ohio.Prev Chronic Dis. 2006;3:A82.

16. Doak CM, Adair LS, Monteiro C, Popkin BM: Overweight and underweight coexist within households in Brazil, China and Russia. J Nutr. 2000;130:2965-2971

17. Caballero B. A nutrition paradox - underweight and obesity in developing countries. N Engl J Med. 2005;352(15):1514-1516.

18. Isanaka S, Mora-Plazas M, Lopez-Arana S, Baylin A, Villamor E. Food insecurity is highly prevalent and predicts underweight but not overweight in adults and school children from Bogota. Columbia. J Nutr. 2007;137(12):2747-2755.

19. Gulliford MC, Mahabir D, Rocke B. Food insecurity, food choices, and body mass index in adults: nutrition transition in Trinidad and Tobago. Int J Epidemiol. 2003;32:508-516.

20. Dubois L, Farmer A, Girard M, Porcherie M. Family food insufficiency is related to overweight among preschoolers. Soc Sci Med. 2006;6:1503-16.

21. Gundersen C, Lohman B, Eisenmann J, Garasky S, Stewart S. Lack of association between adolescent-specific food insecurity and overweight in a sample of 10-15 year old low-income youth. J Nutr. 2008; $138: 371-8$

22. Bhargava A, Jolliffe D, Howard LL. Socioeconomic, behavioral and environmental factors predicted body weights and household food insecurity scores in the Early Adolescent Longitudinal StudyKindergarten. Br J Nutr. 2008; 100: 438-44

23. Keino S, Plasqui G, van den Borne B. Household food insecurity access: a predictor of overweight and underweight among Kenyan women. Agriculture \& Food Security. 2014;3:2. DOI:10.1186/20487010-3-2

24. Rose D, Bodor J. Household food insecurity and overweight status in young school adolescents: results from the early adolescent longitudinal study. Pediatrics. 2006;117:464-73.

25. Centers for Disease Control and Prevention. Defining overweight and obesity. Available at: http://www.cdc.gov/healthyweight/ assessing/bmi/adult_bmi/index.html. Accessed May 15, 2015.

26. Dastgiri S, Tutunchi H, Ostadrahimi A, Mahboob S. Sensitivity and specificity of a short questionnaire for food insecurity surveillance in Iran. Food Nutr. Bull. 2007;28(1):55-8.

27. Cheng S, Kamano J, Kirui NK, Manuthu E, Buckwalter V, Ouma K, et al. Prevalence of food insecurity in patients with diabetes in western Kenya. Diabet Med. 2013;30(6):e215-22.

28. Seligman HK, Jacobs EA, Lopez A, Sarkar U, Tschann J, Fernandez A. Food Insecurity and Hypoglycemia Among Safety Net Patients with Diabetes. Arch Intern Med. 2011;171(13):1204-6.

29. Moreno G1, Morales LS, Isiordia M, de Jaimes FN, Tseng CH, Noguera C, et al. Latinos with Diabetes and Food Insecurity in an Agricultural Community. Med Care. 2015; 53(5):423-9.

30. Bawadi HA, Ammari F, Abu-Jamous D, Khader YS, Bataineh S, Tayyem RF. Food insecurity is related to glycemic control deterioration in patients with type 2diabetes. Clinical Nutrition.
2012;31(2):250-4.

31. Alaimo K, Briefel R, Frongillo E, Olson C. Food insufficiency exists in the United States: results from the Third National health and Nutrition Examination survey (NHANES III). Am J Public Health. 1998;88:419-26.

32. Boushey H, Brocht C, Gundersen B, Bernstein J. Hardships in America: the real story of working families. Washington, DC: Economic Policy Institute; 2001.

33. Hakim S, Dorosty AR, Eshraqian MR. Relationship Between Food Insecurity and Some of Socioeconomic Factors with BMI among Women in Dezfoul. J Sch Public Health Inst Public Health Res. 2011;2: 55-66. [In Persian].

34. Gholami A, Foroozanfar Z. Household food security status in the Northeast of Iran: a cross-sectional study. Islam Repub Iran 2015; 29: 227.

35. Karamsoltani Z, Dorosty AR, Eshraghian MR, Siassi F, Djazayeri A. Obesity and Food Security in Yazd Primary School Students. Tehran Univ Med J. 2007;7:6876. [In Persian]

36. MohammadpourKoldeh M, Fouladvand MA, Avakhkismi, M. Food Insecurity as Risk Factor for Obesity in Booshehrian Low-Income Women. Iran South Med J. 2011;13(4):263-272. [In Persian]

37. Mohammadzadeh A, Dorosty AR, Eshraghian MR. Household Food Security Status and Associated Factors among High-School Students in Esfahan, Iran. Public Health Nutr. 2010;13(10):1609-1613.

38. Rose D, Oliveira V. Nutrient intakes of individuals from food insufficient households in the United States. Am J Public Health. 1997; 7:1856-61.

39. Laraia BA, Siega-Riz AM, Gundersen C. Household food insecurity is associated with selfreportedpregravid weight status, gestational weight gain, and pregnancy complications. J Am Diet Assoc. 2010;110(5):692-701.

40. Martin K, Ferris A. Food insecurity and gender are risk factors for obesity. J NutrEdu Behav. 2007;39: 31-6.

41. Wilde P, Peterman J. Individual weight change is associated with household food security status. J Nutr. 2006;136:1395-400.

42. Tanumihardjo S, Anderson C, Kaufer-Horwitz M, Bode L, Emenaker N, Haqq A, et al. Poverty, obesity, and malnutrition: an international perspective recognizing the paradox. JADA. 2007; 107:1966-72

43. Gucciardi E, Vahabi M, Norris N, Del Monte JP, Farnum C. The Intersection between Food Insecurity and Diabetes: A Review. Curr Nutr Rep. 2014;3:324-332.

44. Rezazadeh A, Omidvar N, Eini-Zinab H, Ghazi-Tabatabaie M, Majdzadeh R, Ghavamzadeh S, et al. Food insecurity, socio-economic factors and weight status in two Iranian ethnic groups. Ethn Health 2016;121(3):233-250.

45. Marjerrison S, Cummings EA, Glanville NT, Kirk SF, Ledwell M. Prevalance and associations of food insecurity in children with diabetes mellitus. J Pediatr. 2011;158(4):607-11.

46. Gucciardi E, Vogt JA, DeMelo M, Stewart DE. Exploration of the relationship between household food insecurity and diabetes in Canada. Diabetes Care. 2009;32(12):2218-24.

47. Wilde PE, Peterman JN. Individual weight change is associated with household food security status. J Nut. 2006; 136(5):1395-1400.

48. Hanson KL, Sobal J, Frongillo EA. Gender and marital status clarify associations between food insecurity and body weight. J Nutr. 2007; 137(6):1460-1465.

49. Hanson KL, SobalJ, Frongillo EA. Gender and Marital Status Clarify Associations between Food Insecurity and Body Weight. J Nutr. 2007; $137: 1460-1465$.

50. Seligman HK, Bindman AB, Vittinghoff E, Kanaya AM, Kushel MB. Food Insecurity is Associated with Diabetes Mellitus: Results from the National Health Examination and Nutrition Examination Survey (NHANES) 1999-2002. J Gen Intern Med. 2007;22:1018-23.

51. Reaven GM. Hypothesis: muscle insulin resistance is the ("not-so") thrifty genotype. Diabetologia. 1998;41(4):482-4. 